\title{
CAPITAL, TRABAJO Y POLÍTICAS SOCIALES DE DESARROLLO EN PROGRAMAS DE ECONOMÍA SOCIAL: CONSIDERACIONES ACERCA DEL MICROCRÉDITO
}

\author{
Daiana Ciancio ${ }^{1}$
}

\begin{abstract}
Resumen: En este trabajo propongo problematizar desde una perspectiva antropológica la forma en la cual las políticas de desarrollo socioeconómico son significadas y re-significadas por los actores sociales que las reciben, diferenciando su experiencia del discurso sostenido desde el ámbito estatal. Para abordar la temática, retomo resultados preliminares de una investigación en curso acerca de un programa de microcréditos implementado desde el Ministerio de Desarrollo Social de la Nación. El grupo seleccionado para el estudio propuesto, es una Asociación Civil de la Ciudad Autónoma de Buenos Aires. Pretendo indagar la relación capital/trabajo a la luz de formas de asalariamiento características de las últimas décadas, que implican una particular configuración de las economías domésticas.

Palabras-claves: microcréditos, relación capital/trabajo, economías domésticas.
\end{abstract}

Abstract: In this paper we propose problematize from an anthropological perspective the way in which economic development policies are re-signified and signified by the social actors who receive them, distinguishing their expierence from State's discourse. To address the issue, I return to preliminary results of an ongoing investigation about a microcredit's program implemented by the Ministry of Social Development of the Argentine Nation. The group selected for the proposed study is a Civil Association of the Ciudad Autonoma Buenos Aires. I intend to explore the relation between capital / labor ratio in the light of forms of employee characteristics in the last decades that involves a particular configuration of the domestic economy.

Keywords: microcredits, ratio capital/work, home economics.

${ }^{1}$ Licenciatura en Ciencias Antropológicas. Facultad de Filosofía y Letras Universidad de Buenos Aires (daiana.ciancio@hotmail.com. 
| 238 |

Capital, trabajo y politicas sociales de desarrollo en...

\section{Introducción}

Como consecuencia de la crisis del Estado de Bienestar hacia la mitad del siglo $\mathrm{XX}$, se generaron amplios debates acerca de cómo resolver la perdida de confianza en el modelo neoliberal, el cual mostraba signos de debilitamiento imposibles de soslayar. Hacia los años '70, y ante una nueva oleada de crisis del capitalismo que se hizo sentir en diversas partes del mundo, surgió la Economía Social y Solidaria. La confianza depositada en el Estado comenzó a ser canalizada hacia la Sociedad Civil, adquiriendo considerable protagonismo ciertas formas cooperativas de producción -que se pretenden alternativas al comercio tradicional- como lo son el Comercio Justo, los Bancos de horas, los Clubes de trueque, etc.

En la mayoría de los casos, la denuncia de una ausencia total o parcial del Estado respecto de la implementación de medidas para contrarrestar la pobreza y la marginación que significa la realidad del desempleo, es sostenida por algunas instituciones de la sociedad civil, como por ejemplo las ONG'S. Éstas, estimulan la Economía Social mediante un sustento económico que normalmente proviene de fondos donados por entes multilaterales internacionales (los cuales donan fondos a fundaciones, instituciones religiosas, etc).

En Argentina, la Economía Social se aplica mediante toda una serie de políticas públicas que diseña el Gobierno desde el año 2003, entre las cuales el microcrédito merece una consideración especial. En el presente artículo, se espera poder dar cuenta de algunas implicancias del Programa de Microcréditos "Padre Cajade" a partir del trabajo de campo en una institución receptora de microcréditos de la Ciudad de Buenos Aires (de ahora en adelante, "SCA"), pero no sólo en su faceta económica sino también respecto de sus implicancias políticas. Asimismo, se pretende exponer algunas consideraciones acerca de las unidades domésticas en tanto sostenedoras de mano de obra que ha sido excluida del mercado de trabajo formal. 


\section{I-Economía Social, microcréditos e inclusión social: Perspectivas}

Si bien no existe una definición unánime acerca de lo que es la Economía Social o Solidaria, sí existen algunos elementos constantes en las diversas perspectivas que definen a este gran campo. Se alude a su carácter alternativo planteándola como "otra economía", aludiendo al componente humano del trabajo, a formas de cooperación, solidaridad, igualdad; también se habla de trabajo autogestionado o autoempleo, entre otras nociones.

Hay básicamente dos tendencias-que discuten entre sí-, desde las que se piensa la Economía Social: una consiste en entenderla como un conjunto de políticas sociales o proyectos que contando con el respaldo de la sociedad civil, funciona cubriendo (de alguna manera) lo que se creen son falencias en el rol que corresponde desempeñar al Estado. Esta perspectiva confía en que la solidaridad, la voluntad y el amor por el prójimo pueden constituir el punto de partida para un mundo distinto, sin injusticia, pobreza y exclusión. Ejemplos de estos postulados son las teorías de J. L. Coraggio (1992), H. Primavera (2004) y Holloway (2006).

La otra perspectiva desde la cual se analiza a la Economía Social, tiene que ver en principio con considerar central el carácter histórico de los procesos económicos y sociales inherentes al desarrollo capitalista, así como también las transformaciones ocurridas desde los años '70 en sus patrones de acumulación y sus consecuencias a nivel global. Desde esta premisa, se entienden los límites de la Economía Social en tanto alternativa a la economía formal. Por su parte, el hecho de que coexista con el capitalismo es comprendido como una cuestión nodal, ya que se parte de la consideración de que para sostenerse a sí mismo, el capitalismo reconfigura (incorporando a su lógica) el funcionamiento de las unidades domésticas, recreando así modalidades preexistentes de comercio, de racionalidad, y también de subjetividad. Ejemplos de estos postulados son las teorías de Presta (2009), Trinchero (1995), Gutierrez Pérez y Trápaga Delfín (1986).

Los distintos proyectos de Economía Social han surgido por lo general alineados con políticas de organismos multilaterales 
| 240 |

Capital, trabajo y politicas sociales de desarrollo en..

de crédito (FMI, BID, CEPAL); los cuales, ante las crisis -y en consecuencia- el crecimiento en los índices de desempleo a escala mundial, han planteado un modelo teórico que pretendió fundamentar una salida a las crisis descomprometiendo al capital de las mismas, no cuestionando el hecho de que el desarrollo de la acumulación capitalista, implica como contrapartida a su expansión un creciente proceso de exclusión y empobrecimiento de sectores sociales en todas partes del mundo. De allí surge la premisa de que el compromiso de la sociedad civil con los "sectores excluidos" podrá combatir la pobreza en donde sea que esta exista. Históricamente, los microcréditos surgen como un modo de lograr - mediante políticas públicas - que los sectores más empobrecidos de las sociedades obtengan ingresos monetarios insertosen una finalidad productiva, y no meramente asistencialista. Conocido es el caso de Muhammad Yunus (2000), quien en la India implementó un sistema de pequeños créditos para los sectores más empobrecidos, el cual benefició a unos doce millones de personas (un sexto del país en ese momento).

Pensando en el microcrédito como una herramienta de la Economía Social, éste es postulado como la vía para lograr que los sectores excluidos del sistema financiero formal puedan acceder a un crédito, como se supone pueden acceder el resto de los trabajadores. Debe tenerse en cuenta en este punto, que en su mayoría los denominados "sectores excluidos" están desempleados, dado que su exclusión del circuito financiero de crédito formal se deriva de no tener un empleo en el mercado de trabajo formal. En contraposición a esta realidad, se postula que la Economía Social lucha por una sociedad más inclusiva, es decir, por una sociedad diferente donde el componente humano del trabajo sea realmente valorizado, dejando de lado la lógica competitiva del mercado. Por su parte, el acceso al microcrédito se presenta como una fuente de trabajo, generada por la propia persona.

Un aspecto muy particular del caso argentino, es que aquí es el mismo Estado quien desde los primeros años de la década del 2000 ha impulsado distintos proyectos enmarcados en lo que se define como "Economía Social". Se destaca lo distintivo de esta 
situación, dado que, como se mencionara más arriba, en general la Economía Social es promovida desde la sociedad civil, en contra de las políticas injustas del Estado.

\section{II - SCA y la dinámica de funcionamiento de los microcréditos}

SCA funciona en un barrio del sur de la Ciudad de Buenos Aires, como sede del Banco de la Buena $\mathrm{Fe}^{2}$, en el marco del Programa de Microcréditos "Padre Cajade", implementado por el Ministerio de Desarrollo Social de la Nación. La institución es una Asociación Civil que se formó hace 28 años, pero en los últimos 4 funciona como un "banquito", es decir, una sede del Banco de la Buena Fe.

El programa "Padre Cajade" es el que promueve y financia el acceso al crédito para aquellos sectores que están excluidos del sistema bancario. Lo hace a través de sus dos instrumentos: los Consorcios de Gestión, que tienen un trato indirecto con las organizaciones beneficiarias del microcrédito; el más importante es $\mathrm{CONAMI}^{3}$. Por otro lado, existen las Redes de Gestión, que tienen un trato directo con las organizaciones beneficiarias, las cuales se nuclean principalmente en el "Banco de la Buena Fe".

En SCA se reúnen actualmente unos 600 emprendedores, que son las personas que llevan adelante los proyectos productivos sostenidos por el Programa de Microcréditos en cuestión. Realizan trabajos en los más variados rubros: producción de miel, cueros, costurería, telar, bijouterie, cocina, entre otros. En todos los casos la condición que impone el Programa Padre Cajade es que el emprendimiento consista en proyectos productivos, de servicios o reventa.

\footnotetext{
${ }^{2}$ El "Banco de la Buena Fe", es el gestor y coordinador del Programa de Microcréditos Padre Cajade a nivel nacional. Funciona como un órgano descentrado del Ministerio de Desarrollo Social de la Nación.

${ }^{3}$ Comisión Nacional de Microcréditos.
} 
En segundo lugar, se encuentra la gente que coordina los proyectos de microcrédito, quienes son denominados "promotores". Por último, también participan de SCA los promotores territoriales ${ }^{4}$, encargados de llevar adelante la "parte política", fundamental en las actividades de la institución. Sobre éste último rol se considerarán algunas cuestiones más adelante.

Respecto de quiénes pueden beneficiarse con la política del Microcrédito, el Ministerio de Desarrollo Social sostiene que "El programa está destinado a emprendedores individuales o asociados, que necesitan dinero para adquirir insumos, maquinaria o para hacer crecer sus emprendimientos productivos pero que, debido a su situación patrimonial, no reúnen las condiciones para acceder a créditos bancarios tradicionales" $"$. Por su parte, se explicita reiteradamente que el Microcrédito no es ni un subsidio ni un pequeño crédito, sino que es definido como "una herramienta más de la Economía Social y Solidaria implementada a partir de la última década, y no un fin en sí mismo ${ }^{6 "}$.

Los integrantes de SCA tienen acceso al Microcrédito gracias a una metodología de "garantías solidarias" y también gracias al "seguimiento-acompañamiento continuo al emprendedor por parte de promotores o asesores de crédito". Desde el Ministerio de Desarrollo Social de la Nación, se sostiene que "(...) el acceso al microcrédito es respaldado por el valor de la palabra, la confianza mutua, la solidaridad entre los emprendedores y los resultados del proyecto. Así, funciona como

\footnotetext{
${ }^{4}$ Las expresiones subrayadas figuran con esa identificación en el relato, debido a que son categorías propias de SCA, y fueron detectadas a partir del discurso de los integrantes del lugar. Para conservar su significación en la mayor medida posible, se las destaca en el presente artículo.

${ }^{5}$ Extraído del Cuaderno de Trabajo №1 de CO.NA.MI (Comisión Nacional de Microcrédito): "Delimitación de la Población Meta del Programa Nacional de Microcrédito".

${ }^{6}$ Extraído del Cuaderno de Trabajo №1 de CO.NA.MI (Comisión Nacional de Microcrédito): "Delimitación de la Población Meta del Programa Nacional de Microcrédito".
} 
un instrumento de inclusión activa de personas y familias en situación de vulnerabilidad al desarrollo económico" ${ }^{7 "}$.

El formato de entrega de los microcréditos consiste en un monto inicial pequeño - entre $\$ 700$ y $\$ 1000$ - que se devuelve semanalmente, implicando desde el $0 \%$ de interés hasta un máximo del 6\% anual, en función del monto recibido. En la medida en que se efectúan las devoluciones en tiempo y forma, los solicitantes pueden llegar a recibir otro crédito de mayor monto, siempre de modo escalonado.

Respecto de las ganancias que genera un emprendimiento de microcrédito, las personas de SCA referían en las conversaciones que teníamos a la potencialidad de incrementarlas en función del trabajo y tiempo que cada emprendedor le dedique a la comercialización de su producto.

Quienes reciben un microcrédito no obtienen un salario a cambio de su trabajo, sino que al postularse su emprendimiento como una forma de autoempleo, lo que cada cual gane depende de sí mismo. Las personas ganan según las cantidades que vendan. En el caso de SCA, las ventas de todos los emprendedores se realizan en ferias que tienen lugar una vez a la semana en la institución. Una situación frecuente, es que los emprendedores vendan sus productos también de modo particular, a clientes conocidos o familiares, en contextos que trascienden la formalidad de la feria semanal, como modo de poder obtener una ganancia complementaria a la feria.

\section{III - Destinatarios del microcrédito en el marco de las unidades domésticas}

Si bien el microcrédito se recibe individualmente (respaldado por la garantía solidaria grupal antes mencionada), según el discurso estatal se espera que esa sea una manera de incluir

\footnotetext{
${ }^{7}$ Fragmentos de la presentación del Programa "Padre Cajade" en la página web del Ministerio de Desarrollo Social de la Nación.
} 
familias enteras en situación de vulnerabilidad social. Quiénes son dichas familias y por qué se encuentran en esa situación, no es algo que se explicite desde el Estado. La condición de vulnerabilidad y exclusión de los sectores empobrecidos no es historizada, sino que aparece como un elemento dado dentro de la realidad social en la que viven los potenciales destinatarios del microcrédito. El Estado se posiciona como externo a la situación de pobreza que se quiere erradicar, culpabilizando al Mercado Económico como si fuera un ente abstracto que excluye continuamente a las personas de su círculo productivo, proceso del cual el Estado aparece desligado. A partir de estos postulados se erige el microcrédito como solución ante la condición de vulnerabilidad social de las familias.

Respecto de este punto, la Antropología Económica se ha servido históricamente de la noción de unidad doméstica para teorizar en diversos sentidos cómo la familia en tanto núcleo social y primordial, constituye por lo menos un importante punto de apoyo o sustento para la actividad económica y social de los individuos que la conforman. ¿Qué ocurre con las unidades domésticas cuando algunos de sus integrantes reciben un microcrédito que "beneficia a todos"? Dado que el microcrédito se presenta como un préstamo solidario, ¿Qué es lo que las unidades domésticas devuelven a cambio de lo recibido? Algunas consideraciones teóricas nos servirán para aclarar este punto.

Tal como sostienen Presta y Landaburu (2008), el hecho de que sea justamente el Gobierno quien impulse la Economía Social, debe entenderse en el marco de los procesos económicos actuales. Las autoras plantean que no es casual que con estas políticas públicas la estrecha relación existente entre los niveles productivo y reproductivo de la unidad doméstica, tienda a desaparecer. Un aspecto recurrente, es que el financiamiento de los microcréditos mantiene los procesos de trabajo de la economía doméstica (por ejemplo trabajar desde la casa, como hacen muchas personas que concurren a SCA), porque aquellos son capaces de solventar la reproducción de sus miembros. Por el contrario, cuando se trata de un empleo en el mercado formal, los trabajadores perciben lo que 
se denomina "salario indirecto", que es la proporción del salario en la cual el empleador costea los gastos de restitución, manutención y reproducción de la mano de obra [(Meillasoux, 1987 y Trinchero (1995)]. Al ser el monto de los microcréditos tan bajo, no cubrir cargas sociales, seguro de vida del trabajador, ni nada de lo que se contempla en un salario convencional, para que un microcrédito resulte viable, es necesario que éste sea parte de un conjunto de ingresos que perciba la familia o entorno doméstico de quien lo solicita, complemento sin el cual se vuelve muy difícil que el microcrédito alcance para reemplazar el salario de un trabajador formal.

La mayoría de los emprendedores que gestionaron su microcrédito a través de SCA, aludieron a que si recibieran el monto del Programa "Padre Cajade" como único ingreso, no podrían sostener ni el emprendimiento ni la devolución monetaria que se pide semanalmente.

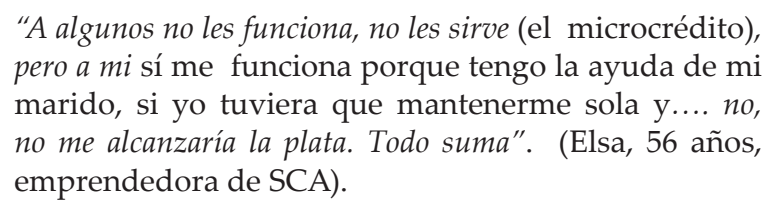

Comentarios como el anterior, eran una constante en los relatos que hacían los emprendedores sobre su experiencia con el microcrédito. Y ocurre que no sólo el monto de los créditos es muy pequeño, sino que en el mejor de los casos las ganancias recibidas por el proyecto (a las que se les deben descontar los gastos que implican la compra de materias primas, pagos a terceros que intervengan en la producción del servicio, etc.) no exceden demasiado el monto que se tiene que devolver. Además, el microcrédito se constituye como viable, como se refirió anteriormente, sólo en los casos en los cuales las personas que lo solicitan cuenten con algún tipo de proyecto productivo en marcha. Si quieren empezar un emprendimiento sin base material alguna, les resulta muy difícil hacer rendir el monto recibido como 
microcrédito para la inversión que implica cualquier compra de cantidades iniciales de insumos, materias primas, máquinas, etc.

La noción "pluralidad de bases económicas" propuesta por Comas D'Argemir (1998), es empleada para definir la articulación en una misma persona, o grupo doméstico, de diferentes tipos de actividades económicas fundadas en relaciones de producción de distinta naturaleza. Ello se debe a que en el proceso de desarrollo y expansión del capitalismo, éste ha subsumido a su propia lógica otras formas sociales y económicas anteriores, integrándolas a sus parámetros de acumulación.

En el caso deSCA es posible observar no sólola diversificación de actividades en pos de la subsistencia del grupo doméstico sino especialmente la coexistencia de relaciones de producción que pertenecen a lógicas aparentemente contradictorias: la de la solidaridad por un lado, y la de la competencia capitalista por otro. En este sentido, la principal condición para posibilitar la situación anterior, es la pluralidad de bases económicas como el pilar de organización sociocultural y al mismo término económica que hallamos al interior de las familias de los emprendedores del microcrédito. De hecho, los integrantes de SCA entrevistados referían a muchos casos en los cuales las personas toman el microcrédito y lo sostienen hasta tanto consiguen un trabajo formal o bien alguno de sus familiares lo hace. Un ejemplo, es el de Betina, quien renovó el microcrédito por un par de años, hasta que consiguió un empleo en el servicio doméstico como mucama,

“(...) y pidió disculpas a su grupo pero dijo que se retiraba del microcrédito porque le rendía más el otro trabajo de empleada doméstica". (Comentario de María, promotora de SCA).

En el Programa "Padre Cajade" 8 , que se postula como inclusivo y el cual se ofrece a todos aquellos que tengan la voluntad

\footnotetext{
${ }^{8}$ www.microcredito.org.ar.
} 
de generar autoempleo ${ }^{9}$, se observan algunas contradicciones dignas de ser consideradas. Por ejemplo, en la "Carpeta de Proyecto"10 en la cual los aspirantes al microcrédito piden su aprobación, se advierte el comportamiento que el emprendedor debe tener y los antecedentes con los que debe contar, con la finalidad de que no se desilusione se el proyecto no le resulta. Existe el supuesto de que llevar a cabo un emprendimiento de manera exitosa, requiere que el sujeto que lo solicita posea no sólo un conocimiento previo suficiente para sostener el proyecto, sino además, y fundamentalmente, una base económica que le permita utilizar el microcrédito como un aporte complementario a sus ingresos. Como se refirió anteriormente, ningún emprendedor de SCA se sustenta exclusivamente con el microcrédito que recibe.

En contraposición a las condiciones, ideales, que se postulan en los lineamientos del Programa de microcréditos, la situación más común por la que las personas que llegan a SCA llegan a convertirse en emprendedores, es que se acercan al lugar a pedir un microcrédito con una intención que no es la que el Programa "Padre Cajade" propone como finalidad. Por ejemplo, para pagar sus impuestos, o para conseguir cierto monto de dinero en efectivo, sin querer continuar el emprendimiento por el que lo reciben.

\section{IV - La lógica del don y la participación política como contraprestación}

Al postularse la Economía Social, e inserto en ella al microcrédito, se propone una alternativa a la lógica del mercado que deshumaniza a los individuos, que los hace competir, que los condena a la exclusión. La solidaridad y la buena voluntad del gobierno a la hora de diseñar políticas públicas para todos (para

\footnotetext{
${ }^{9}$ Extraído del folleto de promoción del Programa "Padre Cajade".

${ }^{10}$ Material que me fue cedido en SCA, el cual es parte de las formalidades con las cuales los potenciales beneficiarios del microcrédito se inscriben en el "Banco de la Buena Fe".
} 
todos los que puedan sostener un emprendimiento productivo y su devolución complementándolo con otros ingresos), se proponen como contrapartida del acto meramente económico del intercambio.

Sin embargo, no todo es pura solidaridad: la devolución del dinero no es lo único que se pide a cambio del financiamiento de un proyecto productivo. Esa solidaridad desde la cual se proclama el microcrédito como herramienta social de inclusión, implica como contraprestación nada más ni nada menos que la participación política de los emprendedores. Cuando desde la Antropología Económica se habla de intercambio y de contraprestación, se hace referencia al don. Godelier (1996) propone que considerar el acto del don en su faceta de dar-donar algo, conduce a una comprensión incompleta de las implicancias del don, ya que todo acto de dar conlleva una contraprestación. Es decir, en tanto constitutivo de los lazos sociales, el don debe ser devuelto.

Sin embargo, para los posicionamientos teóricos que avalan la Economía Social y Solidaria, la peculiaridad del don radica en que

\begin{abstract}
A diferencia del intercambio, en que los sujetos participantes son movidos por el propio interés, la motivación del donante es en muchos casos altruista, manifestándose en ella gratuidad y generosidad. Ambas persiguen maximizar la utilidad y beneficio con recursos escasos, pero mientras en una se trata de utilidad para sí mismo, en la otra se busca la utilidad para terceros. (...) A su vez, las donaciones refuerzan los vínculos de pertenencia y los lazos comunitarios, (...) promueven al beneficiario y favorecen la expansión de sus propias capacidades para satisfacer en el futuro de manera crecientemente autónoma sus necesidades. (Razeto, 2004, p. 3).
\end{abstract}

Si retomando la perspectiva de Godelier, pensamos en el microcrédito como donación solidaria, debemos entonces preguntarnos por aquello que se espera a cambio en el comportamiento de los emprendedores. En el caso de SCA, la devolución del don trasciende la esfera económica (es decir, no 
basta con devolver el monto prestado en tiempo y forma); se trata también de una contraprestación de tinte político, que compromete a los individuos con la actual gestión gubernamental.

Al principio de este artículo, se destacaban las particularidades del caso argentino, en el cual es el propio Estado quien gestiona políticas públicas con la Economía Social como principio. Pues bien, la inclusión social ha sido una de las premisas con las cuales desde el año 2003 el kirchnerismo ha enarbolado su proyecto "Nacional y Popular". En SCA, hay un tercer rol que ocupan algunas personas, sobre el cual es momento de destacar algunas cuestiones. Se trata de los promotores territoriales (que a veces también desarrollan las funciones de promotores, y otras no, dedicándose exclusivamente a la parte política). Su tarea, es distribuirse dos o tres barrios por persona, y el promotor territorial se compromete a recorrerlos cotidianamente, con el propósito de hacerle comprender a la gente por qué tiene que apoyar el modelo económico de la gestión actual, y lograr

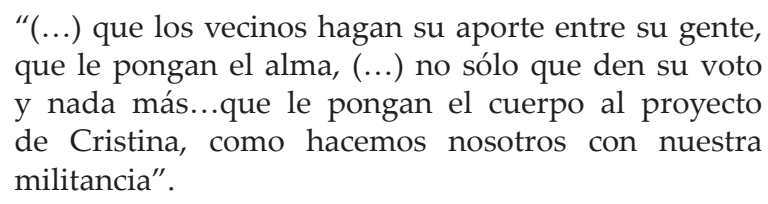

Estas palabras en boca de una promotora territoral, Ana M., describieron el rol de los promotores territoriales en ocasión de una reunión que se organiza mensualmente en SCA, para evaluar cómo se están desarrollando sus objetivos. A cambio de esta tarea, quienes la llevan adelante reciben "una ayuda" (así le llaman ellos mismos) que es monetariamente equivalente al microcrédito. Algunas personas en SCA, me comentaron que es muy frecuente que se empiece como emprendedor del microcrédito, y luego terminen dedicándose de lleno a las actividades de compromiso, de ponerle el cuerpo al proyecto nacional y popular"11 dejando de pedir

${ }^{11}$ Expresión de María, Promotora Territorial de SCA. 
los microcréditos, cediéndoles su lugar a otros. Casualmente las personas que dentro de SCA dejaron de renovar sus microcréditos, son las que más ganancias obtenían de ellos. Claro que la participación política no es una obligación dentro de la institución, pero resulta paradójico que quienes se abren camino mediante la participación política, puedan sostener su emprendimiento por los contactos que el Ministerio de Desarrollo Social puede generarles para percibir montos de crédito más altos, por ejemplo, para destinarlos a la compra de maquinarias.

\section{Consideraciones finales}

A partir de la experiencia de distintas personas que son parte de SCA, hemos visto que en general el microcrédito no es para ellos -como apunta el discurso sostenido por el Estado- un ingreso económico estable, ni principal. En la mayoría de los casos, las personas sostienen sus emprendimientos temporalmente hasta tanto consigan un empleo en el mercado formal, o bien como un ingreso complementario. Esta situación no se condice con las expectativas que el Gobierno tiene sobre la implementación del Programa de Microcréditos "Padre Cajade", al sostener que

\footnotetext{
"Con el acceso al microcrédito, el sujeto de la Economía Social se posesiona como una fuerza social amplia, heterogénea, diversa, que debe agruparse para consolidar y profundizar el proyecto nacional y popular que lo reconoce como sujeto de cambio".
}

Podemos leer entrelíneas este fragmento, y ver cómo se devela el secreto que el gobierno propone a los sectores excluidos para salir de su condición. Los sujetos de cambio son compelidos a militar, a participar del proyecto nacional y popular, para expandir un modelo económico que se supone que los salvará.

El microcrédito en este punto se vuelve una más de las tantas políticas sociales que benefician ciertamente a muchos sectores, aunque su implementación dista -según la perspectiva 
que se ha sostenido en el presente artículo-, de ser una fuente de autoempleo para dichos sectores. El problema estructural de la relación explotadora entre capital y trabajo continúa siendo una cuestión a resolver.

Por último, si bien no se pretende desarrollar el debate aquí, es oportuno repensar la idea de los microcréditos como fuente de trabajo y su relación con la precarización laboral característica del último siglo ${ }^{12}$. Al respecto, Eskenazi y Marticorena (2010) proponen un análisis de las transformaciones en el mundo del trabajo en tanto éste es una relación social de producción. Retomando esta perspectiva junto a la de Presta y Landaburu (2007), podemos afirmar que en las últimas décadas la dirección que siguieron los procesos de subsunción del trabajo en el capital, ha derivado en que cada vez sean más frecuentes ciertas formas de trabajo que antes eran consideradas "informales" o "precarias". Tal es el caso de los trabajadores del microcrédito.

Cuando se estimula, y no por casualidad desde el Estado, la idea de empleos alternativos quebenefician grupos domésticosenteros -como es el caso del auto-emplearse pidiendo un microcrédito del que se beneficia toda la familia del solicitante-, estamos ni más ni menos que ante formas emergentes de asalariamiento del trabajo antes consideradas como trabajo "en negro" o incluso ilegal.

A lo largo del presente artículo, se trató de demostrar a partir de un caso concreto (SCA), cómo es que la idea del microcrédito como sinónimo de empleo está en estrecha conexión con la participación política de los sectores económicamente vulnerables en el modelo de la actual gestión gubernamental, considerando críticamente el carácter solidario y desinteresado que se plantea tienen las políticas de desarrollo como solución de la pobreza y exclusión social.

${ }^{12}$ Para un análisis histórico de esta cuestión, ver Presta (2009). 
Capital, trabajo y politicas sociales de desarrollo en...

\section{Bibliografia}

COMAS D' ARGEMIR, D. Antropología Económica. Barcelona: Ariel, 1988.

CORAGGIO, J. L. "Experiencias de Desarrollo Local con diferentes énfasis: político, institucional, sostenibilidad, cultural". In: Seminario Internacional sobre Desarrollo Económico Local, 25 al 27 de julio de 2007, Bogotá D.C., Colombia. Página Web: www. ungs.edu.ar, 2008.

CORAGGIO, J. L. La Economía Social como vía para otro desarrollo social. http://www.urbared.ungs.edu.ar, 1992.

ESKENAZI, M. y MARTICORENA, C. "Reflexiones críticas acerca de la relación entre precariedad laboral y trabajo asalariado". En: Revista Herramienta Web $\mathrm{n}^{\circ}$ 6, Versión online.. http:// www.herramienta.com.ar/herramienta-web-6/reflexionescriticas-acerca-de-la-relacion-entre-precariedad-laboral-ytrabajo-asa, 2010.

FUKUYAMA, F. Capital social y desarrollo: la agenda venidera. In: Atria Raúl, Siles M, Arraigada, I, Robinson L y Whiteford S. (comp.). Capital social y reducción de la pobreza en y el Caribe; en busca de un nuevo paradigma. CEPAL. Universidad del Estado de Michigan, ISBN, Santiago de Chile, 2003.

GODELIER, M. El enigma del don. España: Paidós, 1996.

GUTIÉRREZ PÉREZ, A. y TRÁPAGA DELFÍN, Y. Capital, renta de la tierra y campesinos. México: Editorial Quinto Sol, 1986.

HOLLOWAY, J. Contra y más allá del capital. Buenos Aires: Ediciones Herramienta, 2006.

LANDABURU, L. y PRESTA, S. Elementos para la reflexión en torno al concepto de unidad doméstica en el contexto neoliberal. In: Revista Papeles de Trabajo $\mathrm{n}^{\mathbf{0}}$ 14, Universidad Nacional de Rosario, 2007. 
MEILLASSOUX, C. Mujeres, graneros y capitales. Madrid: Siglo XXI, 1985.

PRESTA, S. y LANDABURU, L. Consideraciones críticas sobre Desarrollo Económico Local y Economía Social. In: Revista Avaliação de Políticas Públicas/ MAPP, Universidade Federal do Ceará. Fortaleza, Brasil, 2008.

PRESTA, S y LANDABURU, L. ¿Totalidad y fragmentación? Consideraciones en torno al concepto de unidad doméstica en el contexto neoliberal. In: VIII Congreso Argentino de Antropología Social, Universidad Nacional de Salta, Facultad de Humanidades, Escuela de Antropología, del 19 al 22 de septiembre de 2006.

PRESTA, S. Cap. II: La Economía Social y Solidaria en el marco de los procesos de transformación socioeconómicos. Tesis (Doctorado), Facultad de Filosofía y Letras - UBA-, Buenos Aires: Mimeo.2009.

RAZETO, L. Centralidad del trabajo y economía solidaria. In: Economía \& Trabajo, Año 2, N. 3, PET, Santiago de Chile: 1994.

RAZETO, L. La teoría de la economía de donaciones: su contribución al desarrollo de la filantropía y responsabilidad social. Página Web: www.urbared.ungs.edu.ar, 2004.

TRINCHERO, H. Economía doméstica y capital. Buenos Aires: Biblos, 1995.

FUENTES, proporcionadas por el Ministerio de Desarrollo Social de la Nación/ Secretaría de Políticas Sociales y Desarrollo Humano/ Subsecretaría de Economía Social.

- "Capital Social para el Desarrollo". Material de trabajo de los Consejos Consultivos. - Documentos de Trabajo del $1^{\underline{0}}$ Congreso Latinoamericano de Microcrédito.

- Plan Nacional de Desarrollo Local y Economía Social "Manos a la obra"

- Plan Nacional de Microcrédito "Padre Cajade"

- Serie de Cuadernos de Trabajo no ${ }^{1}$. CONAMI. 
